\title{
THE ROLE OF SPEECH THERAPY IN THE HEAD AND NECK SERVICE
}

\author{
M.I. DINNER, M.B., B.Ch. (RAND), F.R.C.S. (LOND), F.R.C.S. (ED.) \\ Consultant Plastic Surgeon to the Head and Neck Clinic at the \\ Johannesburg General Hospital.
}

\section{SUMMARY}

The vital role of the speech therapist, in the multi-disciplinary approach to the rehabilitation of patients subjected to ablative surgery for malignant disease of the head and neck region, is reviewed. The role of the surgical techniques of speech rehabilitation of the laryngectomised patient, who has failed to respond to the therapist's instruction in oesophageal speech rehabilitation, is high-lighted. The deliberate pharyngeal fistula created from the pharynx to the skin surface, is connected by a "speech device" to the tracheostomy stoma. The diversion of expired pulmonary air into the pharynx allows for immediate articulation.

\section{OPSOMMING}

'n Oorsig word gegee van die belangrike rol van die spraakterapeut in die multi-dissiplinêre benadering tot die rehabilitasie van pasiënte wat ablatiewe chirurgie van die kop en nek gehad het vir kwaadaardige toestande. Rehabilitasie met spraak in die laringek tomie pasiënt sluit chirurgiese tegnieke in, in gevalle waar esofagele spraakonderrig deur die terapeut onsuksesvol was. Die opsetlike faringeale fistel tussen die farinks en vel word aan die tracheostomie stoma gekoppel deur middel van 'n ,,spraak apparaat". Die omlejding van uitgeasemde pulmonale lug deur die keelholte maak direkte fonering moontlik.

The role of the speech therapist in rehabilitation of communication in patients who have been subjected to surgery of the head and neck region, is an essential phase in the return of these patients to a useful and meaningful existence with their families and in their communities.

Ablative surgery for the cure of carcinomatous lesions involving one or other of the anatomical structures vital for normal articulation is responsible for the condition referred to as "the surgically induced dysarthrias".

Ablative surgery for any lesion involving:

the tongue

the floor of the mouth

the alveolar margin

the soft or hard palate

the pharynx

the larynx

is frequently radical and extensive. Together with the heroic attempts at sal- 
vaging the patient from his disease, are the concomitent drawbacks of extensive cosmetic disfigurements, and the functional disabilities of dysphagia and dysarthria.

The rehabilitation in these patients to a level of social acceptability in the surgically induced dysarthrias, represents a very trying challenge to the speech therapist in such a unit. A team approach on the head and neck service is responsible for the very marked improvement in duration and quality of survival of these unfortunate patients. Where surgery is adjudged the treatment of choice by the team, the team approach becomes conspicuous. The team of "drastic surgeons" will commit themselves to as wide and extensive surgery as is required to ensure cure, to be followed by a team of "plastic and reconstructive surgeons" who will primarily reconstruct the defect to the limit s of physical possibility, thereby fulfilling two of the first important aims of the treatment of such patients:

1. to cure the patient of his disease

2. to restore his cosmetic deformity to as near normal physical appearance as possible.

It is at this stage that the vital role of the 'speech therapist becomes obvious, in order to eventually enable this patient to communicate adequately. These patients experience great difficulty in attempting to articulate due to either the loss of the lip obicularis muscle, or of tongue musculature or loss of mandibular support for the tongue or floor of the mouth musculature. They must of necessity be taught the art of substitute movements in order to articulate the sounds producing intelligible speech.

However it is the re-education and rehabilitation of speech in the alaryngeal patient that remains the greatest challenge to the speech therapist in such a unit.

\section{SPEECH REHABILITATION IN THE LARYNGECTOMISED PATIENT}

The patient, who for the price of cure of cancer of the larynx must be subjected to total laryngectomy with or without removal of the pharynx, is immediately exposed to the traumatic disability of the inability to communicate. The rehabilitation of the laryngectomee in the majority of cases involves the learning of the techniques of oesophageal speech. This requires the controlled expulsion of swallowed air from the stomach and oesophagus and the articulation of this air as it enters the oral cavity. This patient must be taught the techniques of rapid swallowing of air and its controlled release through the pharyngeal musculature and through the crico-pharyngeal sphincter. ${ }^{1}$ This method is both laudible and reliable in many cases. However it is in those estimated one-third of laryngectomised patients who remain resistant to the speech therapist's every efforts and that never acquire the art of oesophageal speech that other methods of rehabilitation have been devised and conceived. It is for this group of patients and for those having undergone a total laryngopharyngectomy in whom the absence of pharyngeal musculature precludes them from developing the techniques of oesophageal speech, that further mechanical and surgical methods of rehabilitation will be discussed. 


\section{HISTORY}

The first attempt at construction of an artificial larynx anti-dated the first laryngectomy by Billroth in 1873. Gussenbauer reported in 1874 on the construction of an artificial larynx with a vibrating reed which transmitted air directly from the tracheostoma into the open pharynx. Later in 1940 the first battery powered instruments were devised which produced a buzzing monotone, which when applied to the skin of the patients" neck, caused "sound" to be transmitted into the pharynx which could be subsequently articulated for speech. Progressive modifications have improved the nature of the sound and subsequent speech produced by the so-called electro-larynx. These substitute laryngees have many inherent drawbacks such as the expense, the repeated battery failure and the cumbersome nature of always having to carry the device, without which the patient immediately becomes non-communicative.

The need to develop a reliable surgical technique for vocal rehabilitation was therefore great. The concept of diverting pulmonary air from the tracheostomy stoma into the oral cavity is not a new one. In the late 1950's Asai in Japan $^{2}$ and Conley in the U.S.A. ${ }^{3}$ designed operations to reconstruct a vibrating mechanism to serve as a sound source for oral communication. The sound source was constructed by creating a pharyngeal fistula, and a skin tube which connected the trachea to the pharyngeal fistula. It was Conley who used a vein graft to connect the trachea to this pharyngeal fistula. The patient could then divert all expired air into the pharyngeal fistula by obliterating the tracheostoma. With this large volume of air entering into the oral cavity, the patient was able to articulate and thereby immediately become communicative. Many problems were encountered with the Asai type of dermal tube, such as stricture of the fistulous tract, and reflux of food and salivary secretions into the trachea and resultant inhalation pneumonia. Such problems remained unresolved with these techniques which led to further developments in the operative techniques.

Figure I

SHOWING TRACHEOSTOMY STOMA AND DELIBERATE PHARYNGEAL FISTULA

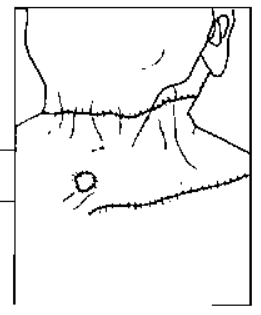

Figure 2

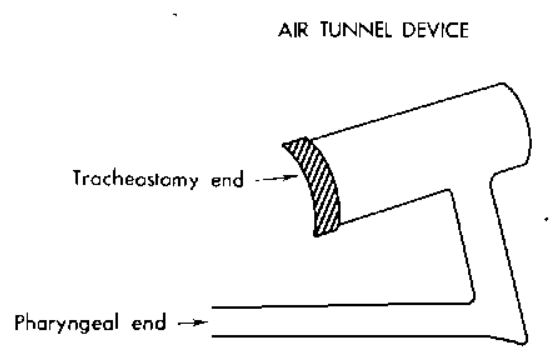

Figure 3

DEVICE IN SITU

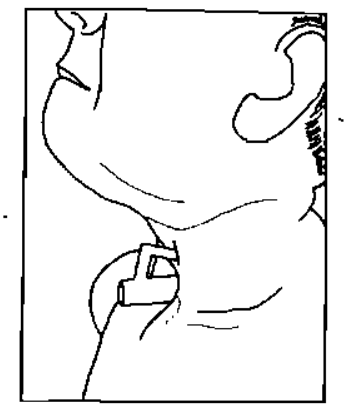


It was Montgomery ${ }^{4}$ who was responsible for the formation of a fistulous tract from the pharynx on to the skin surface. (Fig. 1). It was decided to connect the tracheostomy to the pharynx by indirect means which would thereby avoid the problem of food and saliva entering the trachea. The operation required the formation of a skin or mucosal lined tube from the pharynx to the cervical skin. The dimensions of the tunnel varies from 3 to $6 \mathrm{~mm}$. in internal diameter and at least $3 \mathrm{~cm}$. in length. The outer end of the tunnel is placed at a higher level than the inner end to discourage the leakage of saliva by the anti-gravity situation of the tunnel. After a period of two to three weeks, allowing the operative site to heal satisfactorily, the tracheostoma could then be directly connected to the pharyngeal fistula by means of a simple device called the "air tunnel device" (Fig. 2) which had a snug fitting attachment of the one end to the tracheostomy stoma and the end piece into the pharyngeal fistula (Fig. 3). Expired pulmonary air was easily diverted from the tracheostomy via this pharyngo-cutaneous tunnel directly into the oral cavity. With each expiratory effort the air is diverted deliberately into the oral cavity for articulation by the patient. All that was required by the speech therapist was to teach the patient to co-ordinate his expiratory efforts and the obliteration of the tracheostoma end of the simple "air tunnel device" in order for the patient to begin speaking.

With increase in sophistication of the devices, a one-way valve was included in the circuit at the pharyngeal end to prevent salivary leak from the pharyngeal fistula.

Further sophistication led to the development and inclusion of a vibrating reed in the circuit of the "air tunnel device". The "Reed-larynx" of Taub and Spiro $^{6,7}$ included a vibrating reed with a basic frequency of 130 c.p.s. The speed and tension of the vibration of this reed could be altered thereby altering the quality, pitch and tone of the sound produced as it entered the pharynx for articulation.

This indeed appeared to be the ideal surgical method of speech rehabilitation of the laryngectomee. Very much less intensive speech therapy was required for such patients to learn to speak in comparison to oesophageal speech. The art of articulation could be very rapidly learnt within two to three weeks of surgery, and speech therapy could then be devoted to the refining of articulation, phrasing and inflection of speech.

Over enthusiasm with surgical reconstruction for the rehabilitation of speech however high-lighted many of the problems associated with any biological

fistula. Although the problems which exist can be mastered by the individual and highly selected patient, these problems remain a drawback to this méthod of speech rehabilitation - i.e. the problems of persistent salivary leak through the fistula, persistent excoriation of the surrounding skin of the neck, and the occasional leakage of saliva and food stuffs in to the tracheostoma. Therefore the "air tunnel" and Reed fistula devices represent a very satisfactory method of speech rehabilitation but only in highly selected patients. The problem remains therefore, to prognosticate which patients will prove resistant to the speech therapists' efforts in the instruction of oesophageal speech, to determine which patients should be submitted to these procedures at the time of laryngectomy. 


\section{INDICATIONS FOR SURGICAL REHABILITATION}

Patients with the extended laryngectomy and laryngo-pharyngectomy which includes the pharyngeal musculature, and therefore precludes the patient from the ability to speak by the oesophageal method, is an indication for the primary reconstruction of such a deliberate pharyngeal fistula for speech rehabilitation.

The creation of a pharyngeal fistula in routine laryngectomy should therefore be retained as a secondary procedure for patients who have failed to respond to the techniques of oesophageal speech.

Objective speech evaluations in the reed fistula and air tunnel device patients, by tests such as selective quantitative measures, measures of intelligibility and selective qualitative measures may highlight certain advantages of these methods of speaking. In addition, an important consideration is the relative short time interval that takes place between the laryngectomy and speech rehabilitation.

However many drawbacks still remain with these fistulae such as the leakage, the excoriation and inhalation. In addition Shedd et $\mathrm{al}^{5}$ have shown on selective quantitative measures of speech proficiency for speakers using the air tunnel, the reed fistula and oesophageal speech, that the general speech effectiveness was not significantly different for either of the three types of speakers. For this reason oesophageal speech remains the overall mainstay for speech rehabilitation in the vast majority of laryngectomised patients, except for the highly selected patient who may be subjected to operation for surgical rehabilitation of speech.

\section{CONCLUSION}

Many problems remain to be solved to restore these unfortunate patients, suffering from malignancy of the "head and neck" region, to a useful existence and social acceptability following radical ablative and curative surgery. The combined multi-disciplinary approach is emphasised in their rehabilitation and it is this approach that is responsible for the advances towards the ultimate goal of cure, cosmetic acceptability, and social communicability.

\section{REFERENCES}

1. Snidecor, J.C. (1962): Speech Rehabilitation of the Laryngectomized Springfield, Illinois, Thomas, 46-72.

2. Asai, R. (1960): Laryngoplasty J. Japan Broncho-Esophagological Soc., $12,1-3$.

3. Conley, J.J. (1959): Vocal Rehabilitation by autogenous vein graft $A n n$. Otol. 68:990.

4. Montgomery, W.W. (1972): Post-Laryngectomy Vocal Rehabilitation Arch. Otol, 95, 76.

5. Shedd, D.P.; Bakamjian, V.; Sako, K.; Schaaf, N.G.; Mann, M.B. (1974): Post-Laryngectomy Speech Rehabilitation by a Simplified Single Stage Surgical Method. Am. J. Surg., 128, 505. 
6. Shedd, D.P.; Bakamjian, V.; Sako, K.; Schaaf, N.G.; Barba S.; Mann, M. (1972): Reed Fistula Speech Rehabilitation After Laryngectomy. Am. J. Surg., 124, 510.

7. Taub, S. and Spiro, R.H. (1972): Vocal Rehabilitation of Laryngectomees. Am. J. Surg., 124, 87.

\section{South African Leading Suppliers of:}

AUDIOMETERS

AUDITORY TRAINERS

HEARING AIDS

SOUND PROOF ROOMS etc.

Contact

ERIC C. LEWIS and

HILLARY J. REICHENBERG

\section{THE NEEDLER WESTDENE HEARING AID ORGANIZATION (PTY.) LTD.}

P.O. Box 28975 , SANDRINGHAM. 2131.

Telephone: 